\title{
A NOTE ON THE USE OF STUART'S TRANSPORT MEDIUM FOR THE ISOLATION OF THE GONOCOCCUS*
}

\author{
BY \\ A. E. WILKINSON \\ The Whitechapel Clinic, London
}

The application of cultural methods to the diagnosis of gonorrhoea in small clinics has been hindered in the past by the lack of laboratory facilities. The gonococcus is fastidious in its nutritive requirements and the culture media used to grow it have been elaborated by empirical methods because we have no exact knowledge of the substances necessary for its growth. In clinics not closely associated with a laboratory, some delay in inoculating specimens taken from patients is unavoidable, and this delay militates against the successful cultivation of the organism. Various transport media have been devised to maintain the viability of the gonococcus until it can be inoculated on to a nutritive medium. Experience with Stuart's transport medium (Stuart, 1946) is reported in this note.

A difficulty encountered with some transport media has been the overgrowth of gonococci by other organisms present in the secretions. Attempts to overcome this by the addition to these media of various dyes and bacteriostatic agents have not been completely successful because the gonococcus is itself very sensitive to these agents. In Stuart's medium the problem is approached in a different way. The medium contains no nutrient material and consists essentially of a buffered semi-solid agar made anaerobic by the addition of sodium thioglycollate. Oxidative processes in organisms held in the medium are cut down to a minimum and growth does not occur until they are transferred to a nutrient medium.

\section{Technique}

The cervical secretions of 204 consecutive patients were cultured by two methods on their first attendance at the Whitechapel Clinic.

\footnotetext{
* Received for publication October 6, 1951.
}

(a) Direct Culture.-The secretion was inoculated directly on to hydrocele agar slopes which were incubated for $48 \mathrm{hrs}$. at $35-36^{\circ} \mathrm{C}$. in the ordinary atmosphere.

(b) Delayed Culture.-Swabs treated with charcoal, according to the method described by Moffett and others (1948), were moistened with the secretion and kept in the transport medium for periods varying from 1 to 52 hrs. before being plated out on chocolate agar plates. These were incubated for $24 \mathrm{hrs}$. at $35-36^{\circ} \mathrm{C}$. in an atmosphere containing $\mathrm{CO}_{2}$ produced by burning a candle in a closed container, followed by a further $24 \mathrm{hrs}$. in the ordinary atmosphere at the same temperature. Organisms were identified as gonococci on the basis of their colonial and microscopical appearance, and a positive oxydase reaction. Fermentation reactions were also carried out on 52 of the 65 strains isolated.

Direct culture on hydrocele agar had been the standard method used in this laboratory for many years. The production of the hydrocele medium presents several difficulties, notably the risk of contamination as it cannot be sterilized after preparation. It is also becoming increasingly difficult to obtain adequate supplies of hydrocele fluid. It was thought that a comparison of these two methods would be of interest with a view to the replacement of hydrocele agar by chocolate agar as a routine medium for culturing the gonococcus. It must be emphasized that the procedure adopted gives a comparison of two techniques, it does not offer a controlled comparison of the efficiency of the two media for supporting the growth of the gonococcus.

\section{Results}

Gonococci were found in the smears and/or cultures in 65 of the 204 cervical secretions examined. The distribution found on analysing the results with regard to the time that elapsed before the 
delayed cultures were plated out is shown in the following Table.

TABLE

GONOCOCCI ISOLATED AFTER VARYING PERIODS OF DELAY

\begin{tabular}{|c|c|c|c|c|}
\hline \multirow{2}{*}{ Results } & \multicolumn{3}{|c|}{$\begin{array}{c}\text { Hours at Room Temperature } \\
\text { before Plating out }\end{array}$} & \multirow{2}{*}{$\frac{\begin{array}{l}\text { Total } \\
\text { Cases }\end{array}}{204}$} \\
\hline & $\begin{array}{c}1-8 \\
\text { (131 cases) }\end{array}$ & $\begin{array}{c}9-24 \\
\text { (46 cases) }\end{array}$ & $\begin{array}{c}25-52 \\
(27 \text { cases })\end{array}$ & \\
\hline$\underset{\text { Positive }}{\text { Delayed }}$ Culture & 40 & 16 & 8 & 64 \\
\hline $\begin{array}{lr}\text { Direct } & \text { Culture } \\
\text { Positive } & .\end{array}$ & 32 & 16 & 4 & 52 \\
\hline $\begin{array}{cr}\text { Cervical } & \text { Smears } \\
\text { Positive } & . .\end{array}$ & 17 & 7 & 6 & 30 \\
\hline $\begin{array}{cr}\text { Smears and Both } \\
\text { Cultures } & \text { Nega- } \\
\text { tive } & .\end{array}$ & 89 & 31 & 18 & 138 \\
\hline
\end{tabular}

The Table shows that gonococci were isolated from more patients by the delayed cultures than by those taken on to hydrocele agar at the time the patient was examined. If the 65 patients whose cervices were found to contain gonococci were uniformly distributed among the three groups whose delayed cultures were plated out after intervals of 1-8, 9-24, and 25-52 hours, the expected incidence in these three groups would be $41 \cdot 2$, $14 \cdot 7$, and 8.6 respectively. These incidences agree closely with those actually found : 40,16 , and 8 . Although the numbers involved are small, they suggest that, even when specimens had to be held in the transport medium for 25-52 hours (as, for example, over a week-end), the chances of isolating gonococci were not greatly diminished. Similar results have been reported by Le Minor and others (1949). These workers, in experiments designed to determine the effect of delay in plating, observed that strains began to be lost after they had been held in the transport medium for more than 24 hours.

The advent of potent antibiotics in the therapy of gonorrhoea has not diminished the importance of accurate bacteriological control of diagnosis and tests of cure. Lack of easily accessible laboratory facilities may hinder the full investigation of patients but it should be appreciated that the use of Stuart's transport medium can do much to bridge the gap between patient and laboratory and thus to facilitate the isolation and precise identification of the gonococcus.

This work was carried out during the tenure of an Insole Scholarship awarded by the British Medical Association.

\section{REFERENCES}

Le Minor, L., Le Minor, S., and Combes, R. (1949). Ann. Inst. Pasteur, 77, 327.

Moffet, M., Young, J. L., and Stuart, R. D. (1948). Brit. med. J., 2, 421 .

Stuart, R. D. (1946). Glasg. med. J., 27, 131. 